\title{
Antibacterial activity of selected siddha herbo-mineral preparations against clinically isolated enterococcus species
}

\author{
Shobha K.L ${ }^{1}$, Bernaitis.L ${ }^{1}$, Akshatha S.J ${ }^{1}$, Revathi P Shenoy ${ }^{2}$, Ramachandra ${ }^{3}{ }^{3}$ \\ ${ }^{1}$ Department of Microbiology, Melaka Manipal Medical College,(Manipal Campus), Manipal University, Manipal \\ ${ }^{2}$ Department of Biochemistry, Kasturba Medical College,Manipal, Manipal University, Manipal \\ 3 Department of Surgery, Kasturba Medical College, Manipal,Manipal University, Manipal \\ *Corresponding author E-mail: shobha.kl@manipal.edu
}

\begin{abstract}
Objective: In siddha medicinal practice the use of plant extracts as well as inorganic natural preparations has a vital role as medicines. The present research in the field of phytomedicine is to evaluate the antibacterial properties of three herbo- mineral siddha drugs (Palakarai parpam, Padikara parpam, Uppu chenduram) on clinically isolated Enterococcus strains.

Materials and Methods: Fifteen bacterial strains isolated from clinical samples were identified as Enterococcus faecalis(7), E. faecieum(8).The susceptibility of the microorganisms to the siddha drugs (Palakarai parpam, Padikara parpam, Uppu chendooram) were screened by disc diffusion method and the effective drug's MIC value was calculated by agar dilution method.

Results: Padikara parpam was considered sensitive against the tested Enterococcus faecalis and Enterococcus faecium .Agar dilution was performed with $1 \%, 0.5 \%, 0.25 \%$ and $0.12 \%$ of the drug dilution. MIC was found to be $0.5 \%$.

Conclusion: The drug Padikara parpam contains essential elements which are considered to be good anti-microbial activity against Enterococcus spp. To conclude, the claim in the siddha system of medicine is scientifically validated.
\end{abstract}

Keywords: Palakarai Parpam, Padikara Parpam, Uppu Chendooram, Siddha Medicine, Antibacterial Activity, Enterococcus species.

\section{Introduction}

Enterococci are common inhabitants of intestinal tracts of humans and animals. They are considered as important causes of hospital acquired infection. They are the second most common cause of nosocomial infections and the third most common cause of nosocomial bacteremia. Enterococci are also important causes of community acquired infection. Microorganisms from endogenous sources subsequently cause infection by invasion of commensal flora which infect because of some alteration in host defenses. The sources and reservoirs that play a role in the resistance to antibiotics of enterococci that are community acquired are not known (Gopinath R. and Prakash M., 2013). The three most commonly isolated species of enterococci from human and bovine clinical samples were E. faecalis, E. faecium, and E. casseliflavus. The percentages of E. faecalis isolated from either infections or indwelling medical devices producing biofilm ranged from 94 to $100 \%$ (Oli A.K. et al., 2012). Enterococcus faecalis, a saprophytic component of the normal enteric flora, can cause severe disease and is among the most commonly isolated gram-positive bacteria in the clinical microbiology laboratory (Sher A. 2009, Verma S. and Singh S.P.2008). It can invade the urinary tract, cause wound infections (peritonitis, surgical infections, and intra-abdominal abscesses), and colonize heart tissue, producing sub-acute or acute bacterial endocarditis (EC) after transient bacteremia associated with a portal of entry in the gastrointestinal or genitourinary tract.( Guzman C.A. et al.,1989).

Infectious diseases are as old as life. Antibiotics are molecular ammunition, which have proven to be a major asset in the fight against infectious bacteria by either killing them [bactericidal] or inhibiting their growth [bacteriostatic].The resistance of pathogenic microorganisms to currently known antibiotics is constantly increasing due to a broad use of antimicrobials in medicine, animal husbandry and agriculture. If no preventive measures are taken, such events will certainly increase with time, this will inevitably lead to the development of novel antibiotics with alternative therapeutic strategies is essential. (Shree Devi M.S. et al., 2011)

Nature always stands as a golden mark to exemplify the outstanding phenomena of symbiosis. Natural products from plant, animal and minerals have been the basis of the treatment of human disease. Today there is an estimate that about $80 \%$ of people in developing countries still relays on traditional medicine based largely on species of plants and animals for their primary health care. (Sheetal Verma and S.P. Singh, 2008).

After several decades of many serious problems with the modern medicine system, several people started ancient systems of medicine like Siddha, Ayurveda and Unani (Anjan G et al., 2012). This is because of the adverse effects which is associated with modern drugs (Handral H K et al., 2012).People are facing so many problems with synthetic drugs (Siva Shankar M.S. et al., 2013).

Siddha medicine is one of the two ancient traditional systems of India (Sathish kumar M et.al). First one is "Ayurveda", which flourished in north India and became popular all over the country and also in abroad, and the second one is "Siddha", which originated from Tamil Nadu, a south-east state of India and practiced mostly in and around areas of its origin (Arjun Ram et al., 2009). 
Siddha system of medicine is one of the oldest systems of medicine in Tamil Nadu, India. (Sathish Kumar et al., 2013)This System of Medicine has been prevalent in the ancient Tamil land, is the foremost of all other medical systems in the world. Siddha has its strong foundation of science laid by siddhars and other sages who aimed at attaining salvation and hence formulated medicines for a longer and healthier life span. The quest for a healthy body and healthy mind has been an incessant urge in human beings all over the world. The present millennium is searching for natural and safe treatment method for the same. In Siddha system of medicine most of the chronic diseases are cured by the medicines prepared from the metal and mineral products namely Parpam, Chendooram, Chunnam etc. (Savarimuthu Michael et al.) The WHO has estimated that approximately 60 to $70 \%$ of the world's population rely on traditional medicine for their health needs (Revathy S S and Murugesan M, 2013). The philosophy of Siddha gives us an understanding of the connection between body, mind and soul offering advice for a more natural healthy living (Arunvanan.M et al., 2013). The traditional medicine literature describes the potential role as a source of many vitamins and a domestic remedy for many disorders like diabetes, cancer, arthritis, infectious disease and many others (Handral H K et al., 2012). Worldwide, infectious disease is the most important cause of death accounting for approximately one-half of all deaths in tropical countries. Perhaps it is not surprising, but what may be remarkable is that infectious disease mortality rates are actually increasing in developed countries, such as the United States (Josephin Sheeba.B and Selva Mohan .T. 2012).

There are a limited numbers of invitro studies on herbo - mineral preparations. Therefore, there is a need to identify antibacterial potential of herbo - mineral products based on diseases for which no medicine or only palliative therapy is available. At this juncture, it is of interest to determine the scientific basis for the traditional use of these herbo - mineral medicines and to evaluate the antibacterial potential of herbo-mineral preparations. (Michael J.S. et al, 2011).

In the present study some clinically used herbo - mineral Siddha drugs such as Palakarai parpam (PLP), Padikara parpam (PDP) and Uppu chendooram (UP) were investigated for antibacterial potential against clinically isolated Enterococcus spp.

\section{Materials and Methods}

\subsection{Drugs}

Authenticated Palakarai parpam (PLP), Padikara parpam (PDP) and Uppu chendooram (UP) drugs were procured from IMPCOPS pharmaceuticals, Chennai. This Siddha formulation was prepared by using standard formulation prepared by an ancient Siddhars, and mentioned in his treatise siddha gunapadam. These commercially available formulations were used for treating various diseases in traditional clinical practice in India and are usually prepared from purified mineral, triturated with decoction of herbal juices. They are generally prescribed in the dose of 100$200 \mathrm{mg}$ day-1 and recommended to be taken with a suitable adjuvant.

\subsection{Isolates}

Fifteen Enterococcus spp were isolated from clinical samples over two months period March and April 2013 from Kasturba hospital, Manipal were included in the study. The strains were isolated from urine, pus, blood samples.

\subsection{Identification}

The isolates were identified up to the genus and species level by Gram's stain, motility testing and conventional biochemical tests using standard microbiological techniques, The isolates were identified as Enterococcus faecalis(7), E. faecieum(8)

\subsection{Antibiotic susceptibility testing}

The stock solution of $1 \%$ each drug was prepared by dissolving 0.1 gram of the drug in $10 \mathrm{ml}$ of distilled water. These drugs were subjected to antibacterial susceptibility by disk diffusion test and interpreted based on zone of inhibition. The disk diffusion assay was performed according to the standards of the Clinical and Laboratory Standards Institute (CLSI, 8th edition).The clinical isolates of Enterococcus was taken and inoculated in peptone water incubated for 4 hours at $37^{\circ} \mathrm{C}$.Inoculum was adjusted to 0.5 Mc Farland standards $\left(1.5 \times 10^{8} \mathrm{cfu} / \mathrm{ml}\right)$. Sterile Swabs were used to seed bacteria onto the Mulleur Hinton Agar plates .Lawn culture of the inoculum was performed on Mueller Hinton agar. As a control strain Enterococcus faecalis (ATCC 35550) was also used. Wells were punched in the agar plates with the help of a sterile borer. $50 \mu \mathrm{l}$ of the prepared $1 \%$ drug was inoculated into wells. Vancomycin disc of $30 \mu \mathrm{g}$ disc potency was used as the control.These plates were incubated at $37^{0} \mathrm{C}$ for 24 hours. The zone of inhibition was measured in millimeter $(\mathrm{mm})$.

\section{Results}

PDP was considered sensitive against the tested Enterococcus faecalis and Enterococcus faecium. Table 1 and Fig 1 .Agar dilution was performed with $1 \%, 0.5 \%, 0.25 \%$ and $0.12 \%$ of the drug dilution was performed .MIC was found to be $0.5 \%$ as indicated in table 1.

\section{Discussion}

In recent years, ethanbotanical and traditional uses of natural compounds, received much attention as they are well tested for their efficacy and generally believed to be safe for human use. They obviously deserve scrutiny on modern scientific lines such as phytochemical investigation, biological evaluation on experimental animal models, toxicity studies, investigation of molecular mechanism of actions of isolated phytochemicals and their clinical trials. It is a best classical approach in search of new lead molecules for management of various diseases. Thorough screening of literature available on herbo - mineral drugs depicted the fact that it is a popular remedy among the various ethnic groups, Vaidyas, Hakims and ayurvedic practitioners for cure of variety of ailments. Following the traditional and folk claims, very little efforts have been made by the researchers to explore the therapeutic potential of these drugs. (Handral H K et al., 2012).

The preliminary preclinical analysis of the test drug "Padikara parpam" revealed the presence of elements having anti-microbial effect. The results obtained from the disc diffusion assay showed that there has been an increasing effect on bacterial growth. The results of the other two drugs above studied demonstrated that, they doesn't exists an excellent antimicrobial activity (1\%) against the Enterococcus spp.

The same drugs are prepared and administered by traditional practitioners for last 400 years as per the text. In recent advance, the Siddha drugs are screened by the researchers of various disciplines for example pharmacologist and other medical and para medicals (Uma K.S. et al., 2012.) Further work on isolation and characterization of active principles from medicinal plants and their pharmacodynamic study using latest techniques would be highly beneficial to human beings, the isolated principles needs to be evaluated in scientific manner using scientific experimental animal models and clinical trials to understand exact molecular mechanism of action, in search of lead molecule from natural resources. (Handral H K et al., 2012). 
Table 1: Zone of Inhibition

\begin{tabular}{lllll}
\hline DRUGS & E. faecalis & E. faecium & E.faecalis (ATCC 35550) & INTERPRETATION \\
\hline PLP & - & - & - & R \\
PDP & $18 \mathrm{~mm}$ & $18 \mathrm{~mm}$ & $18 \mathrm{~mm}$ & $\mathrm{~S}$ \\
UP & - & - & - & $\mathrm{R}$ \\
VANCOMYCIN $(30 \mu \mathrm{g})$ & $17 \mathrm{~mm}$ & $17 \mathrm{~mm}$ & $17 \mathrm{~mm}$ & $\mathrm{~S}$ \\
\hline
\end{tabular}

Palakarai parpam (PLP), Padikara parpam (PDP) and Uppu Chendooram (UP).

$\mathrm{R}=$ resistant, $\mathrm{S}=$ sensitive

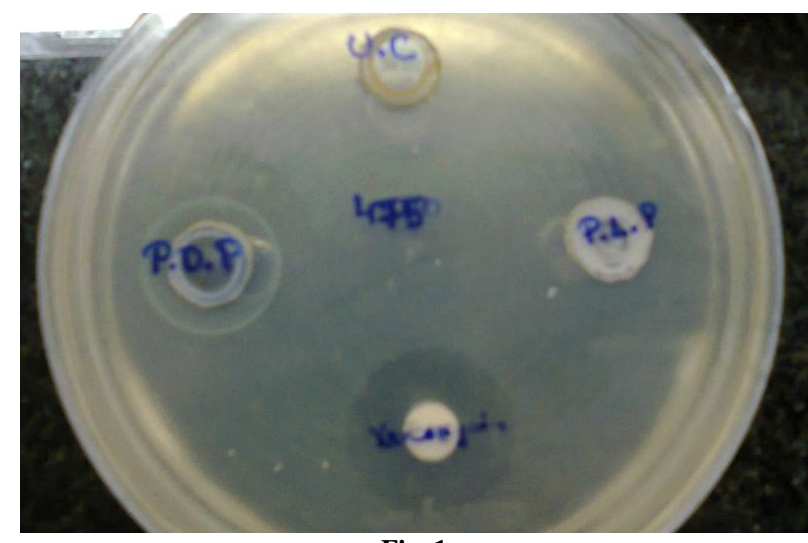

Fig. 1 and its ingredients. IJPI'S Journal of Pharmacology and Toxicology, Vol 1:3.

[15]Siva Shankar M.S., Shree Devi M.S., Sampath Kumar B (2013) Phytochemical Analysis and Antimicrobial Activity Studies of Sirukurinjan Ver Powder. Sch. Acad. J. Biosci.; 1(3):102-103.

[16]Uma K.S., Jacob M., Arumugam G., Kalpana S. and Natarajan M (2012) In Vitro Antimicrobial Activity of the Siddha Drugs Seenthil Sarkarai and Nilavembu Kudineer against Leptospira. International Journal of Pharmacy and Pharmaceutical Sciences. Vol 4, Suppl 2.

[17] Verma S. and Singh S.P.(2008) Current and future status of herbal medicines. Veterinary World, Vol.1 (11): 347-350.

\section{References}

[1] Anjan G., Nagesh L., Sapna B (2012). Evaluation of antimicrobial potential of $10 \%$ ginger extract against streptococcus mutans, candida albicans and enterococcus faecalis - an in-vitro study. International Journal of Science Innovations and Discoveries. 2 (1). 260-265.

[2] Arjun Ram, Duraisamy Arul Joseph, Selvakumar Balachandar, Vijay $\mathrm{Pal}$ Singh. Medicinal plants from Siddha system of medicine useful for treating respiratory diseases. International Journal of Pharmaceuticals Analysis, ISSN: 0975-3079, Volume 1, Issue 2 (2009) pp-20-30.

[3] Arunvanan.M, Sasi.S.K, Mubarak.H, Kanagarajan.A (2013) an overview on anti-diabetic activity of siddha medicinal plants. Asian Journal of Pharmaceutical and Clinical Research .Vol 6, Suppl 2

[4] Austin A. and Jegadeesan M.99. Standardisation of 'Lingha Chendooram' - Number 1, a Siddha Drug. Ancient Science of Life Vol. No. XIX

[5] Gopinath R. and Prakash M (2013) Antibacterial activity of three medicinal plants against clinically isolated multidrug resistant Enterococcus faecalis (MDRE). Int.J.Curr.Microbiol.App.Sci 2(2):614.

[6] Guzman C.A., Pruzzo C., Lipira G, and Calegari L. (1989) Role of Adherence in Pathogenesis of Enterococcus faecalis Urinary Tract Infection and Endocarditis. Infection and Immunity. p. 1834-1838 Vol. 57, No. 6.

[7] Handral H.K., Pandith A., Shruthi S. D (2012) a review on murraya koenigii: multipotential medicinal plant. Asian Journal of Pharmaceutical and Clinical Research .Vol 5, Suppl 4.

[8] Josephin Sheeba.B and Selva Mohan. T (2012) Antimicrobial activity of Adhatoda vasica against clinical pathogens. Asian Journal of Plant Science and Research. 2 (2):83-88.

[9] Michael J S, Ranjith Singh A. J .A. and Padmalatha C. (2011) Antibacterial potential of some herbo-mineral siddha preparation: An alternative medicine for enteric pathogens. J. Chem. Pharm. Res. 3(3):572-578.

[10]Oli A.K., Raju. S, Rajeshwari, Nagaveni. S and Kelmani C. R (2012) Biofilm formation by Multidrug resistant Enterococcus faecalis (MDEF) originated from clinical samples. J. Microbiol. Biotech. Res. 2 (2):284-288

[11]Revathy S.S. and Murugesan M (2013) Physico Chemical Analysis and Anti-Microbial Activity of a Siddha Herbo Mineral Drug. Silasathu Paavanai. Int J Pharm Bio Sci .4(2): (P) 215 - 221.

[12]Sathish Kumar M., Rao M.R.K., Ganesan A., Rengasundari G. (2013) Antibacterial Screening of Kodasuri Veeravaippu, A Siddha Salt Preparation. Int. J. Pharm. Sci. Rev. Res., 20(1); n 23, 140-141.

[13]Sher A (2009) Antimicrobial Activity of Natural Products from Medicinal Plants. Gomal Journal of Medical Sciences, Vol. 7, No. 1.

[14]Shree Devi M.S., Sampath B. and Siva Shankar M.S (2011) Antimicrobial and analgesic activity of traditional Siddha formulation 